\title{
BMJ
}

\section{Trends in mortality from 1965 to 2008 across the English north-south divide: comparative observational study}

\author{
John M Hacking, senior research officer, ${ }^{1}$ Sara Muller, statistician, ${ }^{2}$ lain E Buchan, professor of public health \\ informatics ${ }^{2}$
}

\section{Manchester Joint Health Unit, Town Hall, Manchester M60 2LA, UK \\ ${ }^{2}$ School of Community Based Medicine, University of Manchester \\ Correspondence to: J M Hacking j.hacking@manchester.gov.uk \\ Cite this as: BMJ 2011;342:d508 doi:10.1136/bmi.d508}

\begin{abstract}
Objective To compare all cause mortality between the north and south of England over four decades.

Design Population wide comparative observational study of mortality.

Setting Five northernmost and four southernmost English government office regions.
\end{abstract}

Population All residents in each year from 1965 to 2008. Main outcome measures Death rate ratios of north over south England by age band and sex, and northern excess mortality (percentage of excess deaths in north compared with south, adjusted for age and sex and examined for annual trends, using Poisson regression).

Results During 1965 to 2008 the northern excess mortality remained substantial, at an average of $13.8 \%$ (95\% confidence interval $13.7 \%$ to $13.9 \%$ ). This geographical inequality was significantly larger for males than for females $(14.9 \%, 14.7 \%$ to $15.0 \%$ v $12.7 \%, 12.6 \%$ to $12.9 \%, \mathrm{P}<0.001)$. The inequality decreased significantly but temporarily for both sexes from the early 80 s to the late 90 s, followed by a steep significant increase from 2000 to 2008. Inequality varied with age, being higher for ages 0-9 years and 40-74 years and lower for ages 10-39 years and over 75 years. Time trends also varied with age. The strongest trend over time by age group was the increase among the 20-34 age group, from no significant northern excess mortality in 1965-95 to $22.2 \%$ (18.7\% to $26.0 \%$ ) in $1996-2008$. Overall, the north experienced a fifth more premature ( $(75$ years) deaths than the south, which was significant: a pattern that changed only by a slight increase between 1965 and 2008.

Conclusion Inequalities in all cause mortality in the northsouth divide were severe and persistent over the four decades from 1965 to 2008. Males were affected more than females, and the variation across age groups was substantial. The increase in this inequality from 2000 to 2008 was notable and occurred despite the public policy emphasis in England over this period on reducing inequalities in health.

\section{INTRODUCTION}

In recent years the UK government has set performance targets for reducing geographical inequalities in health, specifically between local authority or primary care trust areas, and has encouraged both to reduce their internal inequalities - for example, at the level of electoral wards. ${ }^{12}$ Statistics on health inequalities are also published at regional level. ${ }^{3}$ In general, the variations decrease as the area of comparison enlarges from electoral ward to local authority or primary care trust to region. This is because the factors producing variation tend to even out as the areas of comparison enlarge. In England, the comparisons commonly made tend to stop at regional level and therefore do not consider larger subnational contrasts. So questions remain: How much variation would be left at the largest possible contrast-namely, of two populations of around 25 million? What would variation between the halves say about structural differences in England? How should the two areas be defined?

One such division in England has considerable historical meaning and continues to be mentioned in comparisons of health and economics - that is, the northsouth divide, ${ }^{4-6}$ with the dividing line usually drawn between the Wash and the Severn Estuary. A recent analysis of health and wealth drew the line further north and east towards the River Humber. ${ }^{7}$ For the present study we adopt the Severn-Wash line because it fits with the boundaries of government office regions, divides the population of England approximately by two, and represents the major division in life expectancy between northern and southern regions. In this arrangement (fig 1), each of the northern regions has poorer health and higher mortality than each of the southern regions. ${ }^{3}$ Government office regions are seen as key geographies for political, economic, and health decisions, each having a dedicated minister and select committee to promote its interests in the latter period of the administration that ran from 1997 to 2010.

Table 1 gives recent statistics on mortality and life expectancy at birth for the nine government office regions. Each southern region has significantly better mortality and life expectancy at birth than the average for England, and each northern region has values that are significantly worse than the average for England. The values for the southern regions are similar, especially among females. Even males in London, with less favourable statistics than for men in other southern 
Table 1| Life expectancy at birth and all age standardised mortality ratios (SMRs) by English government office region, 2006-8, according to Office for National Statistics

\begin{tabular}{|c|c|c|c|c|}
\hline \multirow{2}{*}{$\begin{array}{l}\text { English government office } \\
\text { regions }\end{array}$} & \multicolumn{2}{|c|}{ Life expectancy (years) at birth, $2006-8(95 \% \mathrm{Cl})$} & \multicolumn{2}{|c|}{ SMR, $2006-8(95 \% \mathrm{Cl})$} \\
\hline & Males & Females & Males & Females \\
\hline North East & 76.5 (76.3 to 76.6$)$ & $80.6(80.5$ to 80.7$)$ & 113.3 (114.4 to 112.2$)$ & $112.6(111.5$ to 113.7$)$ \\
\hline North West & $76.3(76.2$ to 76.4$)$ & $80.6(80.5$ to 80.7$)$ & 113.1 (112.4 to 113.8$)$ & $111.9(111.2$ to 112.6$)$ \\
\hline Yorkshire and Humber & 77.1 (77.0 to 77.2$)$ & $81.3(81.2$ to 81.4$)$ & 106.2 (105.4 to 107.0$)$ & 105.8 (105.1 to 106.5$)$ \\
\hline East Midlands & 77.8 (77.7 to 77.9$)$ & $81.8(81.7$ to 81.9$)$ & 101.4 (100.6 to 102.2$)$ & 102.1 (101.3 to 102.9$)$ \\
\hline West Midlands & 77.2 (77.1 to 77.3$)$ & $81.6(81.5$ to 81.7$)$ & $105.8(105.1$ to 106.6$)$ & $102.8(102.1$ to 103.5$)$ \\
\hline East & 78.9 (78.9 to 79.0$)$ & $82.8(82.7$ to 82.8$)$ & 93.3 (92.6 to 94.0$)$ & 95.5 (94.8 to 96.2$)$ \\
\hline London & 78.2 (78.1 to 78.3$)$ & 82.7 (82.6 to 82.8$)$ & 96.4 (95.7 to 97.1$)$ & 93.5 (92.8 to 94.2$)$ \\
\hline South East & 79.2 (79.1 to 79.3$)$ & 83.0 (82.9 to 83.0$)$ & 91.1 (90.6 to 91.7) & 93.6 (93.1 to 94.1$)$ \\
\hline South West & $79.0(78.9$ to 79.1$)$ & 83.1 (83.0 to 83.2 ) & 92.1 (91.4 to 92.8 ) & 92.4 (91.8 to 93.0$)$ \\
\hline All England & 77.9 (77.9 to 78.0$)$ & 82.0 (82.0 to 82.1$)$ & 100.0 (99.8 to 100.2$)$ & 100.0 (99.8 to 100.2$)$ \\
\hline
\end{tabular}

regions, are still much better off than their northern counterparts. The five northern regions show some longitudinal variation and roughly divide into two groups-namely, East Midlands and West Midlands, and Yorkshire and Humber, and the North West and North East: the former group have similar values, which are much worse than those of the southern government office regions but not as extreme as those of the North West and North East. The mean values for the first northern group are closer to the second northern group than to the southern group; therefore aggregation of the two northern groups into one is reasonable. So the empirical north-south dividing line for mortality by government office regions equates to the line that would be chosen on the simple basis of either halving the English population or taking historical precedent.

The long history of the north-south divide in health and economics is well documented. ${ }^{4}$ The persistent north-south divide in health in England has posed a public health challenge, as well as a political and economic challenge to successive governments. ${ }^{48}$ Although the concept of the general north-south divide only came into public consciousness in the late 18th century ${ }^{9}$ evidence for its existence goes back to 1066. ${ }^{10}$ Its persistence begs questions about causality.

Little quantitative research has been done of time trends in this divide. A recent study ${ }^{11}$ showed a worsening trend in health inequalities in Britain from 1990 to 2007; however, despite being based on data for geographical areas the study did not indicate the actual geography of the inequalities. Several authors have reported analyses of trends in regional variations ${ }^{12-14}$ that showed the north-south divide qualitatively. The Department of Health made reference to the divide in an annual overview of health statistics at regional level only. ${ }^{315}$ One study examined the trend in standardised mortality ratios for the north compared with the south of England (defined as aggregates of the National Health Service health regions, in place from 1966 to 1985). ${ }^{16}$ The result was a stable north-south ratio of about 1.13 between 1966 and 1981, followed by an increase up to 1985 . This finding was used to argue for a greater share of NHS resources for the north.
Mortality, or premature ( $<75$ years) mortality, from all causes is a reliable measure for comparing the overall health experience of large geographical areas over time because it has been gathered with little bias for many years. Thus health policy targets are commonly set using mortality rates or life expectancies - in England these are monitored by the Office for National Statistics at the level of local authorities, primary care trusts, and, sometimes, regions. Comparisons at larger geographical levels may indicate different and major problems with policies. Given the government policy emphasis from 1997 to 2010 on regenerating deprived areas and reducing inequalities in health, the northsouth divide might reasonably be expected to have closed because the north has more deprived areas and poorer health. We examined trends in mortality in the north-south divide from 1965 to 2008.

\section{METHODS}

For the geographical analysis we divided England into two halves of longitude based on separating regions of above average mortality from those of below average mortality, consistency with previous comparisons of north and south, consistency with policy relevant regions, and balancing the population size into two approximately equal halves. Using these criteria we set the dividing line between the current nine government office regions into the five northernmost (North East, North West, Yorkshire and Humber, East Midlands, West Midlands) and the four southernmost (East, London, South East, South West), which produces a boundary between the Wash and the Severn Estuary similar to that suggested by both recent ${ }^{6}$ and historical $^{4}$ data. Although regional boundaries have changed in the past 40 years, it is still possible to divide the regions into north and south, with consistent boundaries. For 1965 to 2008 the average northsouth population ratio was 0.984 for males and 0.977 for females. These ratios changed significantly over this period (males from 1.050 to 0.910 and females from 1.030 to 0.910 ) as the population of the south grew faster than that of the north.

We chose 1965 to 2008 to cover and hence validate the previous basic analysis from 1966 to $1985,{ }^{16}$ 


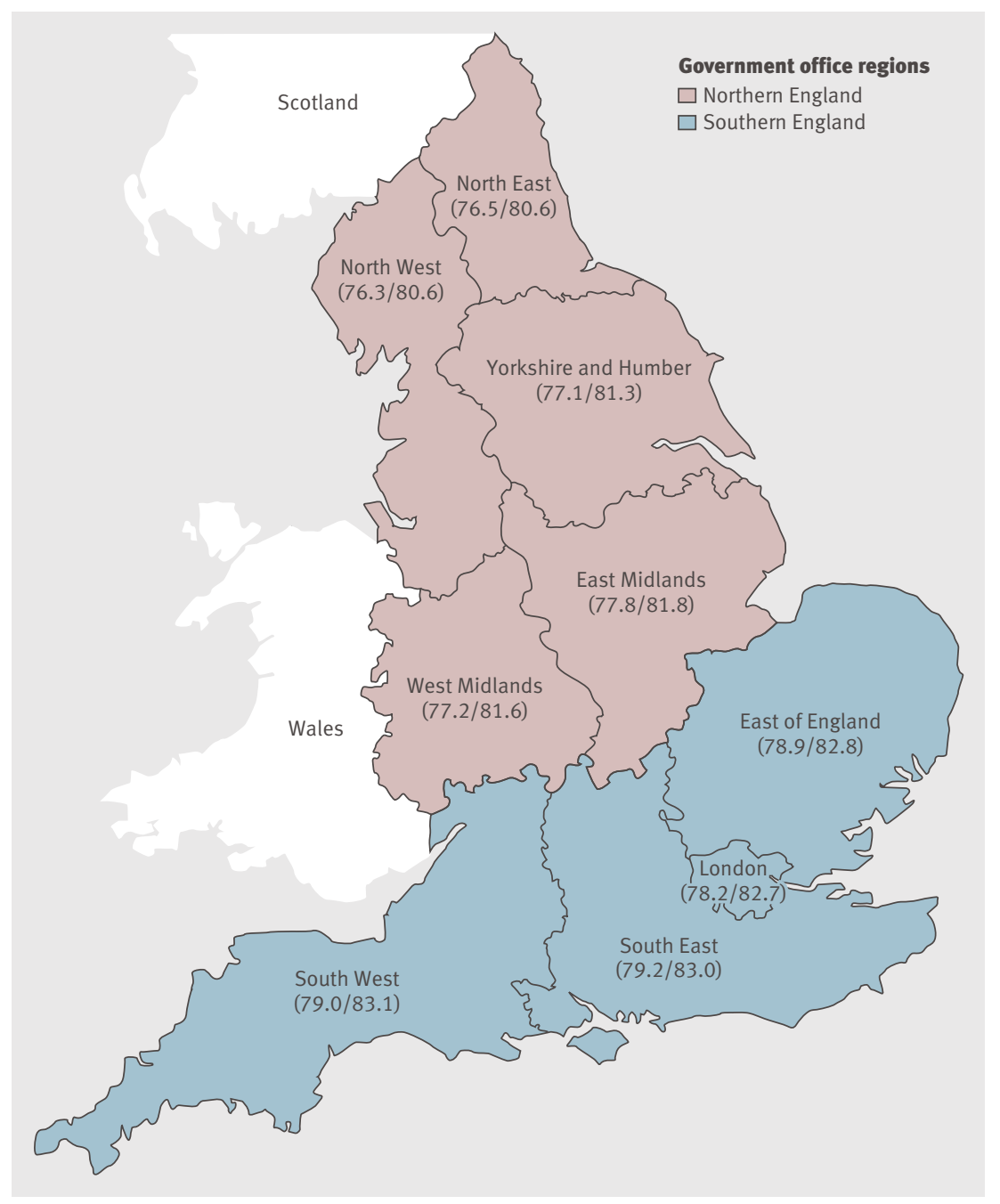

Fig 1| Boundaries of government office regions in north and south of England showing life expectancy of both sexes (males/females) at birth, 2006-8. Boundary data adapted from Ordnance Survey
The death and population counts were provided for age groups $<1$ year (infant), 1-4 years, and five year age bands up to age 85 . To adjust crude mortality rates for age and sex we constructed a Poisson model with the outcome as death, an offset equal to the natural logarithm of the mid-year population size estimate, and including sex and age groups as categorical covariates.

A reference population size to standardise across the years was not needed, because the only statistic drawn from each year was an incidence rate ratio, for which north and south were compared after standardising for age and sex across England, within the relevant year.

From the Poisson models we investigated the differences in mortality between north and south England as age and sex adjusted incidence rate ratios. We present the incidence rate ratios as the percentage of excess deaths in the north compared with the south after adjusting for differences in age and sex, which we define as northern excess mortality. Each year was considered separately in the regression models, then we examined the incidence rate ratios as an annual series, plotted in various subgroups. Statistics from the Poisson modelling are presented as the main effect, with $95 \%$ confidence intervals.

\section{RESULTS}

Around half a million deaths occur each year in England. Over the period of this study the annual number of deaths decreased from 516317 in 1965 to 475763 in 2008. This reduction resulted from decreasing age specific mortality rates, particularly in recent years. The size of the decrease in numbers of deaths was masked by the $14.1 \%$ expansion in population, from 45.071 million in 1965 to 51.445 million in 2008. The general population increase was much greater in the south than in the north $(21.9 \% v 6.7 \%$, respectively). The decrease in numbers of deaths was also masked by the increase over time in the proportion of the population in older age groups, which have higher death rates.

The age at which people die has gradually shifted upwards. In 1965-7, 33.8\% of men (north 31.5\%, south $36.3 \%$ ) and $53.7 \%$ (north $50.7 \%$, south $56.7 \%$ ) of women were living beyond 75 years; by $2006-8$ the corresponding percentages had increased, to $58.0 \%$ (north 56.1\%, south 60.1\%) and 74.2\% (north 72.7\%, south $75.7 \%$ ). At the same time the all age standardised mortality ratio for England decreased for males by $49.2 \%$ (49.1\% to $49.3 \%$ ) and for females by $38.0 \%$ $(37.8 \%$ to $38.1 \%)$. This decrease was slightly larger in the south for males and in the north for females; for males the decrease was $48.8 \%(48.7 \%$ to $49.0 \%)$ in the north compared with $49.5 \%(49.4 \%$ to $49.7 \%)$ in the south and for females was $39.2 \%(39.0 \%$ to $39.4 \%)$ in the north compared with $37.2 \%$ (37.0\% to $37.4 \%)$ in the south.

\section{Mean northern excess mortality by age band}

The mean number of excess deaths in the north compared with the south for 1965 to 2008 varied widely by age band (fig 2). For all age bands the mean northern excess mortality was greater than zero. the Office for National Statistics. The death cor were for deaths registered in the particular year. We calculated death rate ratios for each year for each sex and age band. 

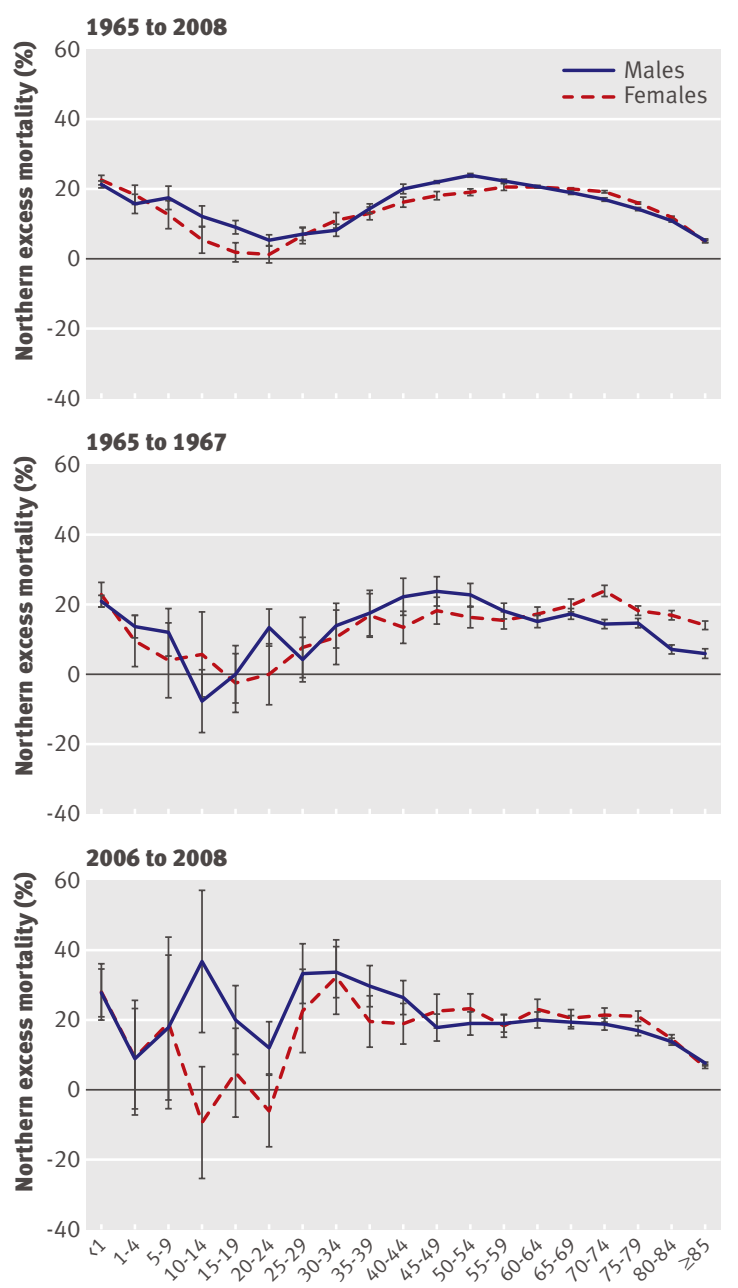

Age band

Fig 2 | Percentage (95\% confidence interval) of northern excess deaths for males and females; mean of years 1965$2008,1965-7$, and $2006-8$ by age band

Patterns for both sexes were similar, apart from ages 10-24 and 40-59, where the northern excess mortality was greater for males. Starting from the youngest age bands, the excess was high for infants, at 21.8\% $(21.0 \%$ to $22.8 \%$ ). The ratio then decreased to a minimum at age 20-24 for both sexes: males at $5.1 \%$ (3.5\% to $6.7 \%)$ and females at $1.2 \%(-1.3 \%$ to $3.7 \%)$. A steep increase then occurred to maxima for: late working life (age 5054 ) in males, at $23.7 \%$ (23.0\% to $24.6 \%)$; and for retirement (age 65-69) in females, at $20.4 \%$ (19.8\% to $21.0 \%)$. The ratios then decreased steeply to low values for the age band 85 or more: males at $4.7 \%(4.5 \%$ to $4.9 \%)$ and females at $4.8 \%(4.5 \%$ to $5.1 \%)$. The decrease in later life reflects the large northern excess mortality in premature ( $<75$ years) deaths in relation to death at any age. Table 2 summarises the mean northern excess mortality over 44 years by age and sex for a selection of age groups reflecting life stages.

The summary over 44 years hides important time trends. For example, the low values for those in early working life hide the fact that the northern excess mortality in this group increased from around zero in
1965-7 to around 25\% in 2006-8 (fig 2). The most striking differences were the worsening northern excess mortality for male children and for young adults of both sexes.

To give an idea of the impact, the number of northern excess deaths from 1965 to 2008 was 876434 (95\% confidence interval 824316 to 928552 ) for males and 771031 (720 018 to 822043 ) for females, equivalent to the total number of deaths in England over about three years. The annual average was 19919 (18 734 to 21 103) for males and 17523 (16364 to 18683) for femalesover 37000 per year for males and females combined. The mean annual number of northern excess deaths in 2006-8 increased with age and reached a maximum for males in the 80-84 age band $(2929,2665$ to 3192$)$ and for females in the 85 or more age band $(3338,2953$ to 3724$)$. The mean number of annual northern excess deaths was smaller for younger ages - in 2006-8 the mean annual northern excess deaths in male infants was 257 (193 to 320) and in female infants was 208 (150 to 266).

\section{Time trends in north-south excess deaths} All ages

Figure 3 shows a northern excess mortality of $15 \%$ for both sexes in the late $60 \mathrm{~s}$ and $70 \mathrm{~s}$, with an overall decrease of $1.4 \%(1.0 \%$ to $1.8 \%)$ per decade. From 1980 to 2000 the excess mortality decreased by $1.6 \%$ $(1.3 \%$ to $1.8 \%)$ per decade, whereas from 2000 the excess increased by $3.8 \%$ (3.1\% to $4.6 \%$ ) per decade.

From the mid-70s the northern excess mortality became greater in men than in women, whereas in the late 60s it had been higher in women. From 1975 to 2008 the male northern excess mortality was $15.0 \%$ $(14.8 \%$ to $15.1 \%)$, whereas in women this gap was $12.5 \%(12.4 \%$ to $12.7 \%)$.

Figure 4 shows northern excess mortality from 1965 to 2008 in both sexes according to the different age groups.

\section{Ages 0-1: infancy}

Among infants, the northern excess mortality was similar between males and females: the excess decreased from $18 \%(15 \%$ to $22 \%)$ in 1965 to non-significant levels in 1987, after which it increased to $29 \%$ (20\% to $38 \%)$ in 2008.

Table 2 |Mean northern excess mortality by age band and sex 1965-2008

\begin{tabular}{llll}
\multirow{2}{*}{$\begin{array}{l}\text { Ages } \\
\text { (years) }\end{array}$} & \multicolumn{3}{c}{ Percentage (95\% confidence interval) } \\
\cline { 2 - 4 } All ages & $13.8(13.7$ to 13.9$)$ & $14.9(14.7$ to 15.0$)$ & $12.7(12.6$ to 12.9$)$ \\
\hline$\langle 1$ & $21.9(21.0$ to 22.7$)$ & $21.4(20.3$ to 22.6$)$ & $22.4(21.1$ to 23.8$)$ \\
\hline $1-19$ & $11.2(10.2$ to 12.2$)$ & $12.3(11.0$ to 13.6$)$ & $9.6(7.9,11.2)$ \\
\hline $20-34$ & $6.8(6.1$ to 7.6$)$ & $6.8(5.8$ to 7.7$)$ & $7.0(5.7$ to 8.3$)$ \\
\hline $35-49$ & $18.4(17.9$ to 18.9$)$ & $19.8(19.1$ to 20.4$)$ & $16.4(15.7$ to 17.2$)$ \\
\hline $50-64$ & $21.1(20.9$ to 21.4$)$ & $21.8(21.4$ to 22.1$)$ & $20.0(19.6$ to 20.5$)$ \\
\hline $65-74$ & $18.5(18.3$ to 18.7$)$ & $17.7(17.5$ to 18.0$)$ & $19.6(19.2$ to 19.9$)$ \\
\hline $\mathbf{7 5}$ & $18.9(18.8$ to 19.1$)$ & $18.8(18.7$ to 19.0$)$ & $19.1(18.8$ to 19.3$)$ \\
\hline 275 & $9.7(9.6$ to 9.8$)$ & $10.1(9.9$ to 10.3$)$ & $9.4(9.3$ to 9.6$)$ \\
\hline
\end{tabular}




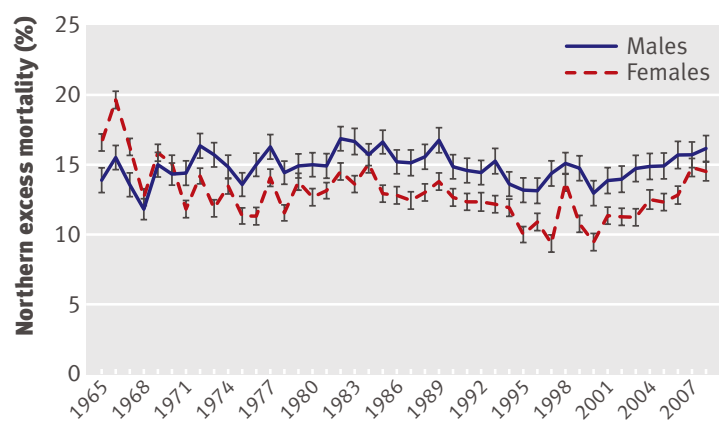

Year

Fig 3 Percentage (95\% confidence interval) northern excess deaths for males and females from 1965 to 2008 by year for all ages

\section{Ages 1-19: childhood and early adulthood}

In the 1-19 age group the northern excess mortality was similar between males and females (fig 4 ). Between 1965 and 1994 the excess was around 8\% (7\% to 9\%), increasing to $15 \%(12 \%$ to $17 \%)$ between 1995 and 2008 , an overall increase of $2.5 \%$ (1.7\% to $3.2 \%)$ per decade.

\section{Ages 20-34: early working life}

In the 20-34 age group the northern excess mortality decreased in males and females by $2.5 \%(1.6 \%$ to $3.4 \%)$ per decade from 1965 to 1993 (fig 4), such that there was no significant difference between north and south from the early 70 s to the mid-90s; a northern excess mortality then emerged sharply, increasing by $13 \%$ $(10 \%$ to $16 \%)$ per decade, to $31 \%(24 \%$ to $37 \%)$ in 2008. Males accounted for more of this recent increase than females.

\section{Ages 35-49: middle working life}

In the 35-49 age group the northern excess mortality between 1965 and 1990 was greater in males than in females by $4.5 \%$ (3.4\% to $5.7 \%$; fig 4 ). Thereafter, the sex distribution of northern excess mortality became more variable. Overall, the curve in northern excess mortality was U shaped from 1965 to 2008 , decreasing by $3.5 \%(2.9 \%$ to $4.0 \%)$ per decade from 1965 to 1993 and then increasing by $13.3 \%(11.6 \%$ to $15.0 \%)$ per decade from 1994 to 2008, back to the levels in 1965 .

\section{Ages 50-64: late working life}

In the 50-64 age group the northern excess mortality increased by $2.6 \%(2.2 \%$ to $3.0 \%)$ per decade (fig 4$)$. During this period the excess in males was generally greater than in females. Despite a slight decrease in northern excess mortality in this age group during the 90 s, another increase in the 2000 s resulted in a higher level of excess mortality in 2008 than in 1965.

\section{Ages 65-74: retirement}

In the 65-74 age group the northern excess mortality in females was substantially higher than in males from 1965 until 1970 (fig 4). After this date, it continued to be higher in females, but not as noticeably. Over the whole period the northern excess mortality increased from $17 \%$ (16\% to $18 \%$ ) in 1965 to $23 \%$ (21\% to $24 \%$ ) in 2008 , at a rate of $0.9 \%(0.7 \%$ to $1.0 \%)$ per decade.

\section{Age $<75$ : premature death}

In the under 75 age group the northern excess mortality was similar for males and females from 1965 to 2008 , increasing inconsistently by around $0.5 \%(0.4 \%$ to $0.6 \%)$ per decade to $22 \%$ (21\% to $24 \%)$ in 2008 . The north therefore had a fifth more premature deaths than the south.

\section{Age $\geq 75$ : late retirement}

In the 75 or more age group the northern excess mortality was slightly higher in females than in males between 1965 and 1970, but between 1970 and 1985 this difference disappeared. Thereafter males showed higher northern excess mortality than females, by $3.2 \%$ (3.0\% to $3.4 \%)$, with neither showing a consistent trend. The trends for both males and females approximately mirror those for all ages from the early 80 s onwards.

\section{DISCUSSION}

The north-south divide in population wide all cause mortality has been both substantial and persistent over the past four decades since 1965 in England, averaging $13.8 \%$ (95\% confidence interval $13.7 \%$ to $13.9 \%$ ) excess deaths in the north compared with the south. The inequality was larger in men than in women (14.9\%, $14.7 \%$ to $15.0 \%$ v $12.7 \%, 12.6 \%$ to $12.9 \%)$. Both sexes had a northern excess mortality that was similar at the end of the study period to that at the start. Trends were significant over shorter periods, such as a gradual reduction for both males and females from the early 80 s to the early 90 s, followed by a steeper increase from 2000 to 2008 . This inequality varied considerably between age groups, being high for infants and those in late middle age and low for young adults and elderly people (age $\geq 85$ ). Time trends in excess deaths also varied with age: the most striking age band was early working life (age 20-34) where the trend in northern excess deaths increased steeply from no significant excess between 1965 and 1995 to an average $22.2 \%$ (21.3\% to $25.1 \%)$ for 1996-2008. Most importantly from a public health perspective, people in the north were a fifth more likely to experience premature $(<75$ years) death than those in the south $(\mathrm{P}<0.001)$, and this difference changed little between 1965 and 2008.

\section{Strengths and weaknesses of the study}

The key strengths of this study are its long duration and large coverage of a national population. We measured the largest scale of geographical health inequality in England, involving two populations of around 25 million people each. The inaccuracies in population estimates that might affect a study examining smaller geographies are less likely to affect this study. Because the two areas being compared were equivalent in size to many countries, any significant differences reflected large scale structural differences rather than local 

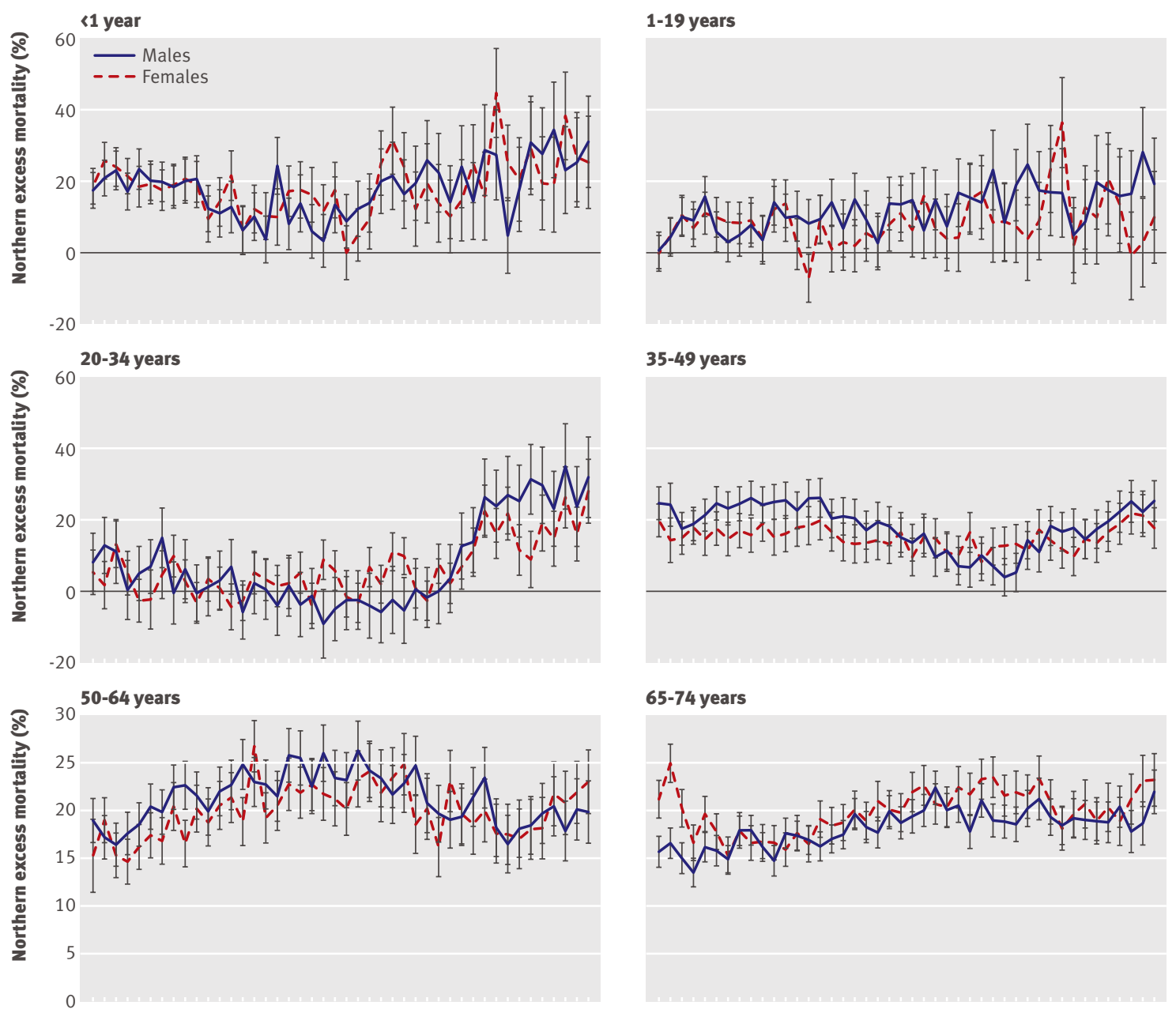

65-74 years
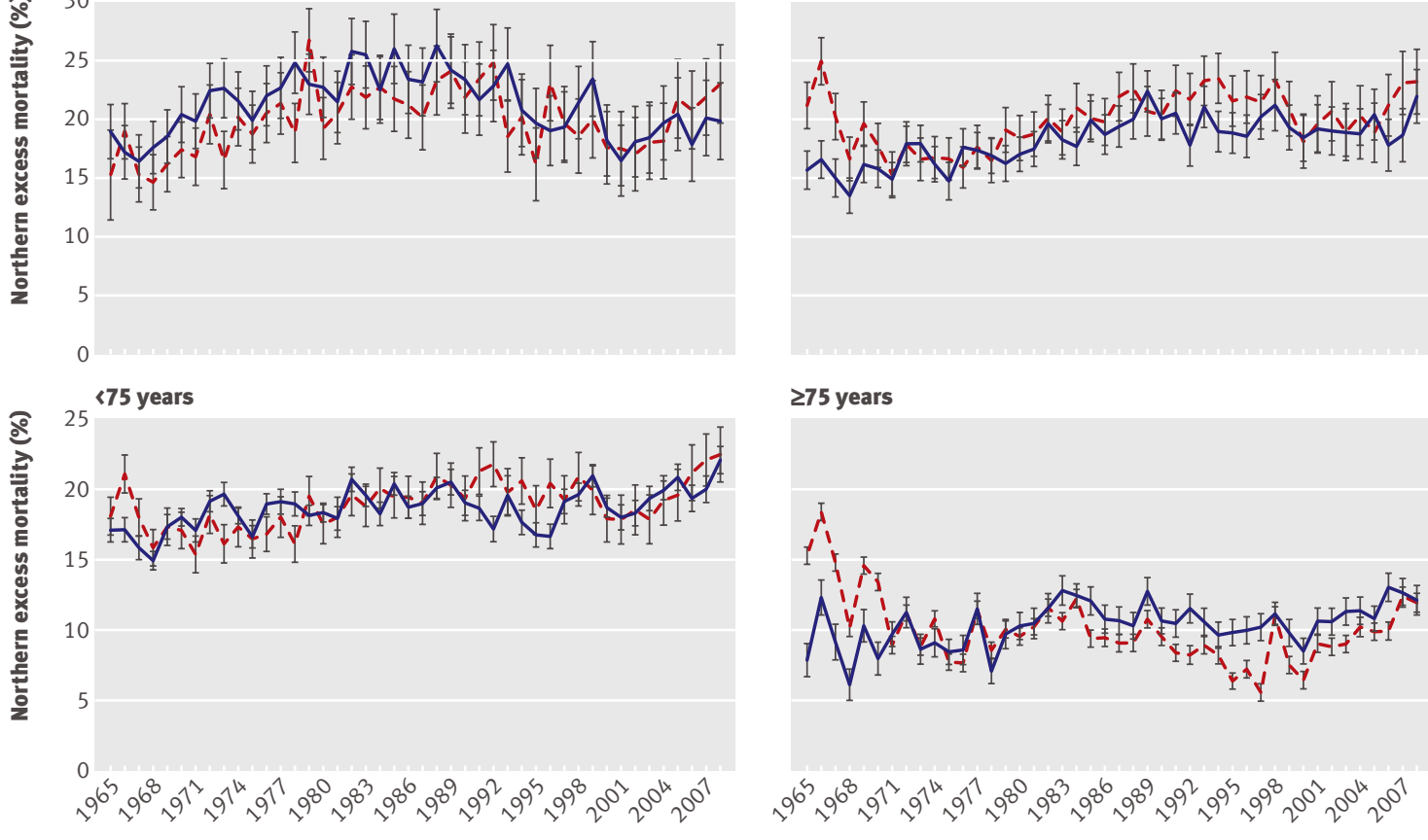

275 years

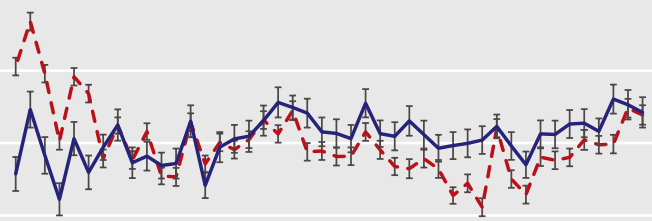

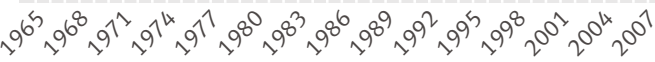

Year

Fig 4 | Percentage ( $95 \%$ confidence interval) of northern excess deaths for males and females from 1965 to 2008 by year in different age groups

variations - the large scale structural differences being an easier target for government policies to tackle health inequalities. An arguable weakness is the arbitrariness in our definition of north and south, by governmental office regions, even though the dividing line approximates well to the Severn-Wash boundary usually associated with the divide and it represents the largest longitudinal step in mortality between the regions. We considered it more important to give relevance to political and administrative boundaries than to fine tune the north-south boundary demographically. Of course any fine tuning would involve some degree of arbitrariness in choice of variables and of size of geographical unit. Before we focused on the north-south picture we examined recent regional variation in mortality, but we did not repeat the work of other studies that have examined mortality trends by government office regions and smaller areas. Therefore we have not determined the relative contributions of the regions to the trends over time in the north-south divide. Such a regional trend analysis would be a separate investigation with a different focus from the 
current one, which was on the neglected relationship between two populations of historical and political importance.

\section{Comparison with previous studies}

Previous studies, apart from one carried out 20 years ago, ${ }^{16}$ considered mortality by smaller geographies, up to the level of government office regions. Therefore the literature gives a largely qualitative account of the English north-south divide in mortality, with no recent quantification. The advances of this study compared with the previous one are the increase in period, 1965 to 2008 compared with 1966 to 1985 ; modelling by sex and age band as opposed to aggregate summaries of all ages and all people; and the incorporation of age and sex structure into specific comparisons by using multivariate models rather than making univariate contrasts of standardised mortality ratios. This study shows that the previous analysis gave only a partial picture of the time trend and assumed that the increase in the early 80 s was a trend that would be continued or the higher level maintained: in fact the trend was just one of a series of rises and falls, with a decrease after 1985 until the late $90 \mathrm{~s}$.

\section{Interpretation of results}

Many factors might plausibly determine the northern excess mortality, including socioeconomic, environmental (including working conditions), educational, epigenetic, and lifestyle, which may act over the whole life course, and possibly over generations. Statistics are available for region specific deaths attributable to smoking $^{3}$ and alcohol consumption. ${ }^{17}$ Aggregation of these results into north and south shows that for 2004-6, 14.0\% of the northern excess deaths for males and females were attributable to the difference in prevalence of smoking, and for 2005 the equivalent figure for alcohol was $3.5 \%$. Such factors are particularly relevant to the worsening inequality in determinants of health among young adults. For men of working age (25-64 years), mortality data from 2001 to 2003 by socioeconomic group and region show the greater proportion of lower socioeconomic groups in the north (mortality in England increases from high to low socioeconomic group) and the greater mortality in the north compared with the south for each socioeconomic group, especially the lower groups. ${ }^{18}$

Recent research highlighted the potential importance of selective migration of healthier people from poorer health areas to better health areas, and vice versa, in explaining the origin, maintenance, and worsening over time of geographical inequalities in health. ${ }^{1920}$ Data on inter-regional migration in England between 1975 and 2008 from the Office for National Statistics show an average annual north to south migration of 181923 people balanced by a south to north migration of 171360 , resulting in a net annual flow of 10563 from north to south. This may support a selective migration hypothesis, but in the absence of information on the health of the migrants it cannot be regarded as evidence. The net migration has oscillated over the period from over 42000 in 1983 to over 35000 (net south to north) in 2003 and the temporal relation with the north-south divide in mortality is likely to be complex.

Further possible determinants of the divide include the distribution of healthcare and public health resources. ${ }^{2122}$ In particular the balance and intensity of public health initiatives have been considered key to reducing inequalities. ${ }^{23}$ Such initiatives, however, may be dwarfed by the health effects of the continuing economic and income disparity between north and south. ${ }^{2425}$ The gross value added per head (a measure of the state of the economy) was $40.4 \%$ higher in the south than the north in 2008, up from 25.0\% in 1989. Figures for disposable income, even after allowing for the higher cost of living in the south, still show a big difference-26.2\% higher in the south in 2008, up from $20.9 \%$ in 1995 . The improvement in the all age divide from the early 80 s to the late 90 s corresponds to adjacent periods of economic recession, whereas conversely the worsening from 2000 coincides with an economic boom when wealth in the south increased faster than in the north. Differences in public spending on transport and research between north and south are large ${ }^{26}$ and the centralisation of power and decision making in London may result in more attention being paid to the south. ${ }^{2728}$ Centralisation of both government and media in the south may cause the public to see the south as a better place to live, ${ }^{29}$ promoting, in conjunction with economic drives, selective migration to the south. In recent years many public health and regeneration initiatives have taken place in poorer health areas and therefore by default more in the north than in the south. Northern excess deaths have, however, increased steadily from 2000 to 2008 . This contrast indicates that the initiatives to reduce inequalities in health were insufficient to overcome the social, economic, and migration forces driving poorer health in the north than in the south.

\section{Context and composition}

The question of causation raises the issue of the balance between context and composition - that is, the extent to which geographical inequalities in health are caused by the external environment in its widest meaning and to what extent by the intrinsic nature of the population. Examples of the context versus composition tension are housing or physical environment versus socioeconomic status. One study ${ }^{30}$ looking at the north-south divide in self rated general health for all social classes found that social mix was only part of the explanation. An earlier study ${ }^{31}$ showed that region accounted for four times more variation in mortality than that explained by the classification of residential neighbourhoods by household type. An analysis of the Office for National Statistics Longitudinal Study ${ }^{32}$ indicated that both socioeconomic disadvantages, as measured by housing tenure and region of residence, were important predictors of regional differences in mortality and the north-south divide. The statistical artefact of regression to the mean might be expected to reduce 


\section{WHAT IS ALREADY KNOWN ON THIS TOPIC}

A longstanding significant north-south divide exists in England for most health metrics

The excess of deaths in the north compared with the south was on average around $14 \%$ from 1966 to 1985 , being lower in the late 70 s and higher in the early 80 s

\section{WHAT THIS STUDY ADDS}

Northern excess deaths from all causes over all ages have been substantial (average 14.9\% for males and $12.7 \%$ for females) from 1965 to 2008

Premature ( 875 years) excess deaths are a fifth higher in the north of England than the south

There is a recent (2000-8) overall trend of increasing northern excess mortality concerning both premature ( $(75$ years) and mature ( $\geq 75$ years) age groups for both males and females

composition differences over time, but this may be counterbalanced by selective migration.

Further research is needed to account for the varying sizes and trends of northern excess deaths by age band. However, the phenomenon of the lower values of northern excess deaths for those in late retirement ( $>75$ years) appears in other studies that compare high with low mortality areas. ${ }^{2}$ The likely explanation is that in the higher mortality area the smaller proportion who survive into the high age bands are by selection a relatively healthy group, with mortality rates that are closer to those of the larger group that survives in the lower mortality areas. The large increase in early working life (age 20-34) from around 1995 may relate to lifestyle factors, although the number of deaths involved is too low to make a major contribution to the recent increase in all ages. This latter is powered by both the age bands for under 75 years and 75 or more years.

\section{Policy implications}

The main implication of our findings is that they point towards a severe, long term, and recently worsening structural health problem in the geography of England, which may not have received the attention it requires from government policy and which has been resistant to specific policies to reduce inequalities in health or to regenerate local communities. It might imply that such policies have not been concentrated enough in the northern half of England or that, for example, a more directed regional economic policy, as in France or Germany, is required. ${ }^{28}$ It might also imply an imbalance between north and south in the wider determinants of health such as education, access to cultural activities, and social capital. ${ }^{33}$ Additionally the idea of psychosocial stresses due to relative position in society and income inequality may be relevant. ${ }^{34}$

\section{Further research}

A natural progression of this work is to analyse mortality trends by region and cause, to give a more detailed picture, and possibly infer more causality. Some more explanatory analysis of the north-south data might be made by incorporating economic and migration factors, although interpretation will need to consider time lags between cause and effect.

\section{Conclusion}

In conclusion, we present the persistence of an English north-south inequality in health over four decades and five governments, during which the north has experienced a fifth more premature deaths than the south. More research is needed into why policies to reduce such inequalities have failed, how the wider determinants of health may be unbalanced between north and south, and the size and drivers of selective migration. The findings are likely to be complex because the determinants of health are complex. So there is a further need for science and public services to collaborate more in building realistically complex but accessible models ${ }^{35}$ to inform policy making.

We thank Neil Bendel of Manchester Joint Health Unit for providing the original maps for fig 1 and Simon Capewell for helpful comments on the manuscript.

Contributors: $\mathrm{JMH}$ had the original idea, obtained the data, carried out initial analyses and interpretation, and wrote the initial draft. IB carried out further statistical analyses and interpretation, and contributed to the writing of all further drafts of the paper. SM and IEB updated the statistical analyses and manuscript for a later/extended edition of the data. All authors had full access to all of the data (including statistical reports and tables) in the study and take responsibility for the integrity of the data and the accuracy of the data analysis.

Funding: The researchers were not specifically funded to do this research. Competing interests: All authors have completed the Unified Competing Interest form at www.icmje.org/coi_disclosure.pdf (available on request from the corresponding author) and declare: no support from any organisation for the submitted work; no financial relationships with any organisations that might have an interest in the submitted work in the previous three years; no other relationships or activities that could appea to have influenced the submitted work.

Ethical approval: Not required.

Data sharing: The dataset is available from I E Buchan at buchan@manchester.ac.uk.

1 Department of Health. World class commissioning assurance handbook. DH, 2007.

2 Department of Health. Tackling health inequalities. 2006-8 data and policy update for the 2010 national target. DH, 2009.

3 Department of Health. Health profile of England. DH, 2008.

4 Baker ARH, Billinge M, eds. Geographies of England, the north-south divide, imagined and material. Cambridge University Press, 2004.

5 Glasmeier A, Martin R, Tyler P, Dorling D. Poverty and place in the UK and USA. Cambridge / Regions Econ Soc 2008;1:1-16.

6 Gordon E, Wells C. Geographical variations in premature mortality in England and Wales, 1981-2006. Health Stat Q 2008;38:6-18.

7 Dorling D. Injustice. Policy Press, 2010: figure 23.

8 Smith D. North and south: Britain's economic, social and political divide. 2nd ed. Penguin, 1994.

9 Billinge M. Divided by a common language 1750-1830. In: Baker ARH, Billinge M, eds. Geographies of England, the north-south divide, imagined and material. Cambridge University Press, 2004:88-111.

10 Campbell BMS. North-south dichotomies 1066-1550. In: Baker ARH, Billinge M, eds. Geographies of England, the north-south divide, imagined and material. Cambridge University Press, 2004:145-74.

11 Thomas B, Dorling D, Davey Smith G. Inequalities in premature mortality in Britain: observational study from 1921 to 2007. BMJ 2010;341:c3639.

12 Leyland $\mathrm{AH}$. Increasing inequalities in premature mortality in Great Britain. J Epidemiol Community Health 2004;58:296-302.

13 Law MR, Morris JK. Why is mortality higher in poorer areas and in more northern areas of England and Wales? J Epidemiol Community Health 1998;52:344-52.

14 Eames M, Ben-Schlomo Y, Marmot MG. Social deprivation and premature mortality: regional comparison across England. BMJ 1993;307:1097-102.

15 Kmietowicz Z. North-south divide persists in England. BM 2006;333:774.

16 Leck I. The north-south divide in England: implications for health care resource allocation. Community Med 1989;11:102-7.

17 Deacon L, Hughes S, Tocque K, Bellis M, eds. Indications of health in the English regions 8: alcohol. North West Public Health Observatory, 2007. 
18 Siegler V, Langford A, Johnson B. Regional differences in male mortality inequalities using the National Statistics Socio-economic Classification, England and Wales, 2001-3. Health Stat Q, 2008;40:6-17

19 Boyle P. Population geography: migration and inequalities in mortality and morbidity. Prog Hum Geogr 2004;28:767-76.

20 Norman P, Boyle PJ, Rees P. Selective migration, health and deprivation: a longitudinal analysis. Soc Sci Med 2005;60:2755-71

21 Gainsbury S. Health inequalities row is shrouded in secrecy. Health Serv J 2008;118:12-3.

22 House of Commons Health Committee. Health inequalities. Third report of session 2008-9. Stationery Office, 2009.

23 Department of Health. Choosing health: making healthy choices easier. Stationery Office, 2004.

24 Hills J, Brewer M, Jenkins S, Lister R, Lupton R, Machin S, et al. An anatomy of economic inequality in the UK: report of the National Equality Panel. London School of Economics and Political Science: Centre for Analysis of Social Exclusion, 2010.

25 HM Treasury. Autumn performance report. 2009. www.hm-treasury. gov.uk/d/autumnperformance151209.pdf.

26 House of Commons. Reducing regional disparities in prosperity. OD PM Housing, Planning, Local Government and the Regions Committee: ninth report of session 2002-3. 2003. www. publications.parliament.uk/pa/cm200203/cmselect/cmodpm/ 492/492.pdf.

27 Martin RL. The contemporary debate over the north-south divide: images and realities of regional inequality in late-twentieth-century Britain. In: Baker ARH, Billinge M, eds. Geographies of England, the north-south divide, imagined and material. Cambridge University Press, 2004:15-43.

28 Parkinson M, Simmie J, Hutchin M, Clark G, Verdonk H. Competitive European cities: where do the core cities stand? Stationery Office, 2004.

29 Howell P. Industry and identity 1830-1918. In: Baker ARH, Billinge M, eds. Geographies of England, the north-south divide, imagined and material. Cambridge University Press, 2004:64-87.

30 Doran T, Drever F, Whitehead M. Is there a north-south divide in social class inequalities in health in Great Britain? Cross sectional study using data from the 2001 census. BMJ 2004;328:1043-5.

31 Langford I, Bentham G. Regional variation in mortality rates in England and Wales: an analysis using multi-level modelling. Soc Sci Med 1996;42:897-908.

32 Harding S, Reid A. An examination of persisting disadvantage and mortality in the regions using the Longitudinal Study. Health Stat $Q$ 2000;6:7-13.

33 Harper R. Social capital: a review of the literature. Office for National Statistics, 2001.

34 Wilkinson R. Socioeconomic determinants of health: health inequalities: relative or absolute material standards? BMJ 1997;314:591.

35 Buchan I, Winn J, Bishop C. A unified modelling approach to data intensive healthcare. In: Hey T, Tansley S, Tolle K, eds. The fourth paradigm: data-intensive scientific discovery. Microsoft Research, 2009.

Accepted: 7 December 2010 